\title{
Sertolioma unilateral como causa de morte súbita por hemorragia interna em ganso Anser cygnoides
}

\author{
[Unilateral Sertolioma as a cause of sudden death by internal bleeding \\ in a Anser cygnoides goose] \\ R. Sesterhenn ${ }^{1}$, T.Z. Ferreira ${ }^{1}$, L.C.B. Fallavena ${ }^{2}$, C. Pianta ${ }^{2}$, \\ H.L.S. Moraes ${ }^{1}$ L. Kindlein ${ }^{1 *}$ \\ ${ }^{1}$ Aluno de pós-graduação - Universidade Federal do Rio Grande do Sul - Porto Alegre, RS \\ ${ }^{2}$ Faculdade de Medicina Veterinária - Ulbra, RS
}

\begin{abstract}
RESUMO
Um ganso adulto macho (Anser cygnoides), da família Anseriformes, de idade desconhecida, proveniente de uma criação da Universidade Luterana do Brasil, foi encontrado morto, sem apresentar histórico clínico, e foi submetido à investigação post mortem no Setor de Patologia Veterinária do Hospital Veterinário. Com base nos achados de necropsia e no exame histopatológico, definiu-se como causa da morte do animal hemorragia interna em razão da ruptura de vasos sanguíneos em uma neoplasia no testículo direito (sertolioma), com metástase no fígado.
\end{abstract}

Palavras-chave: ganso, hemorragia interna, morte súbita, neoplasia testicular, tumor de células de Sertoli

\begin{abstract}
An adult male goose (Anser cygnoides) of unknown age, raised at the Lutheran University of Brazil, was found dead without showing clinical history and was submitted for post mortem investigation in the Department of Pathology of the Veterinary Hospital. From the necropsy and histopathological findings, the cause of death was defined as exsanguination due to intestinal hemorrhage from ruptured vessels in a tumor in the right testis, which also presented hepatic metastasis.
\end{abstract}

Keywords: goose, internal bleeding, sudden death, testicular neoplasm, Sertoli cell tumor

\section{INTRODUÇÃO}

Diferentes tipos de neoplasias testiculares têm sido descritas em aves, sendo a maioria classificada como teratomas gonadais ou seminomas, ambas com etiologia desconhecida ou não comprovada (Beach, 1962; Rossi et al., 2003; Santos e Angélico, 2004).

Ganorkar e Kurkure (1998) descreveram um caso de seminoma bilateral em um pato Mallard de quatro anos de idade (Anas platyrhynchos), que foi recebido para necropsia proveniente do zoológico Maharajbag, em Nagpur, Índia. Dois dias antes da morte, a ave encontrava-se apática, sem nenhum outro sinal clínico marcante. A condição corporal do animal estava boa. Na necropsia, verificou-se que ambos os testículos estavam aumentados e ocupavam a maioria da cavidade celomática, o fígado estava comprimido e apresentava dois cistos hidáticos.

Mutinelli et al. (2006) relataram um outro caso de seminoma unilateral com metástases viscerais também em um pato Mallard (Anas platyrhynchos) de três anos de idade, pertencente a um grupo de 31 patos selvagens de vida livre. Reportaram que a ave estava deprimida dias antes de ser apresentada para exame clínico, sendo depois submetida à eutanásia. $\mathrm{Na}$ abertura da cavidade celomática, verificou-se que o testículo direito apresentava-se significativamente maior. Além

Recebido em 1 de outubro de 2012

Aceito em 20 de dezembro de 2013

*Autor para correspondência (corresponding author)

E-mail: liris.kindlein@ufrgs.br 
disso, nódulos ásperos esbranquiçados eram evidentes sobre o pâncreas e o peritônio visceral. Ao exame histológico, confirmou-se a presença de seminoma com metástases hepáticas, pancreáticas, pulmonares e peritoneais.

Blackmore (1966) e Reece (1992), em pesquisas realizadas com aves comerciais, de zoológico, de criadores, de vida livre e de companhia, observaram que a família dos Anseriformes apresenta baixa prevalência de neoplasias.

$\mathrm{Na}$ literatura, foram encontrados relatos de tumores de células de Sertoli em classes de aves como galinha doméstica, espécies de psitacídeos, codorna japonesa e diamante-de- Gould, entretanto não foi relatada morte súbita nesses casos (Siller, 1956; Petrak e Gilmore, 1982; Gorham e Ottinger, 1986; Rossi et al., 2003).

O presente trabalho objetiva relatar a morte súbita de um ganso sinaleiro Anser cygnoides por hemorragia interna, em razão de um sertolioma no testículo direito.

\section{CASUÍSTICA}

Um ganso sinaleiro Anser cygnoides, adulto, do sexo masculino, proveniente de uma criação no campus da Universidade Luterana do Brasil (Ulbra), no município de Canoas/Rio Grande do Sul, de latitude $29^{\circ} 55^{\prime} 04^{\prime}$ 'S e longitude $51^{\circ} 11^{\text {' }}$ 01 ', $\mathrm{W}$, foi encontrado morto, sem ter apresentado anteriormente sinais de enfermidade, e foi encaminhado ao Setor de Patologia Veterinária do Hospital Veterinário da Universidade.

$\mathrm{Na}$ ocasião da necropsia, a carcaça apresentavase intensamente pálida e, à abertura da cavidade celomática, observou-se que ela encontrava-se totalmente preenchida por sangue coagulado. Após a remoção deste, notou-se a presença de massa esbranquiçada de aproximadamente $15 \mathrm{~cm}$ de diâmetro na região contralateral ao testículo esquerdo. A massa apresentava superfície irregular e numerosos nódulos de diâmetro variável, consistência firme e uma área extensa de hemorragia que causava protrusão para a superfície (Fig. 1-a). Nódulos de aspecto semelhante foram visualizados na superfície do fígado (Fig. 1-b). O testículo esquerdo e as demais vísceras não apresentavam anormalidades.

Ao corte, tanto a massa tumoral como os nódulos hepáticos apresentavam consistência firme e coloração cinza-esbranquiçada a amarelada, sendo frequentes áreas dispersas de hemorragia. Amostras representativas da massa tumoral, dos nódulos hepáticos e das demais vísceras (rins, coração, cérebro, pulmão, pró-ventrículo e moela, além do testículo esquerdo) foram coletadas, fixadas em formalina a $10 \%$ e processadas conforme método rotineiro para exame histopatológico e, posteriormente, foram coradas pelo método de hematoxilina e eosina (Luna, 1968).

O exame histopatológico da massa tumoral mostrou neoplasia testicular diagnosticada como tumor de células de Sertoli, caracterizando-se por células epiteliais arranjadas em paliçada na parede de estruturas tubulares, com núcleos volumosos e densos na região basal das células e dispostos em um citoplasma basofílico. Em algumas áreas da massa neoplásica, as células formavam lóbulos e cordões separados por um estroma delicado (Fig. 2).

Áreas de necrose e de hemorragia foram frequentes na massa neoplásica, assim como figuras de mitose. Os nódulos na superfície hepática apresentaram o mesmo padrão histológico, tendo sido considerados metástases do tumor primário do testículo direito (Fig. 3). 


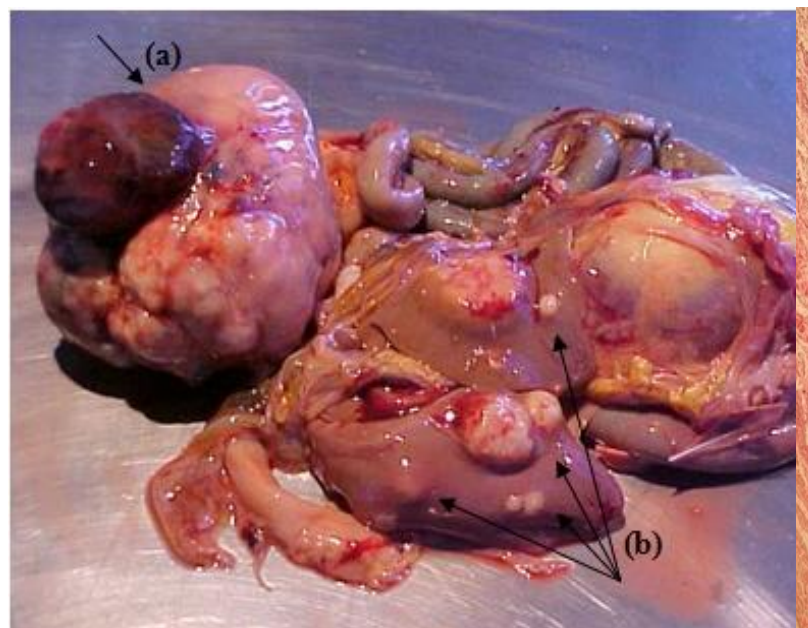

Figura 1. Testículo neoplásico com protrusão hemorrágica (a) e fígado apresentando nódulos metastáticos (b).

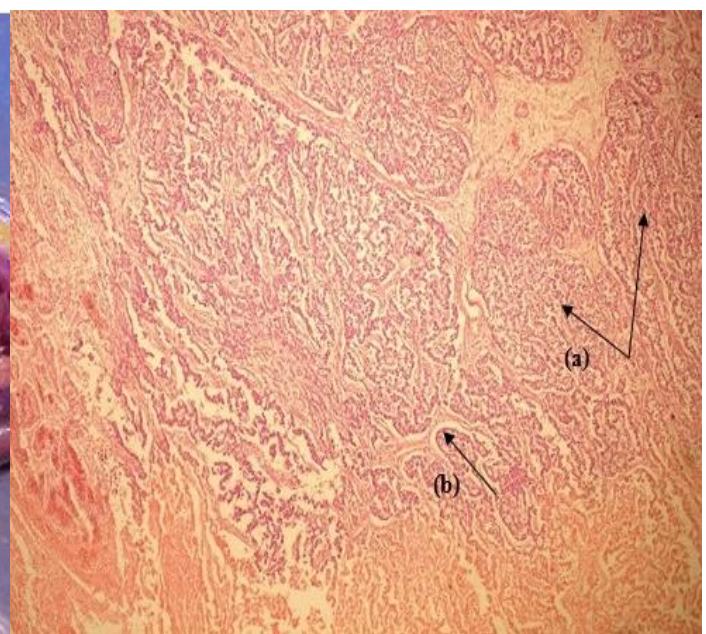

Figura 2. Testículo com sertolioma, formação de lóbulos (a) e cordões separados por um estroma delicado (b) (HE 40x).

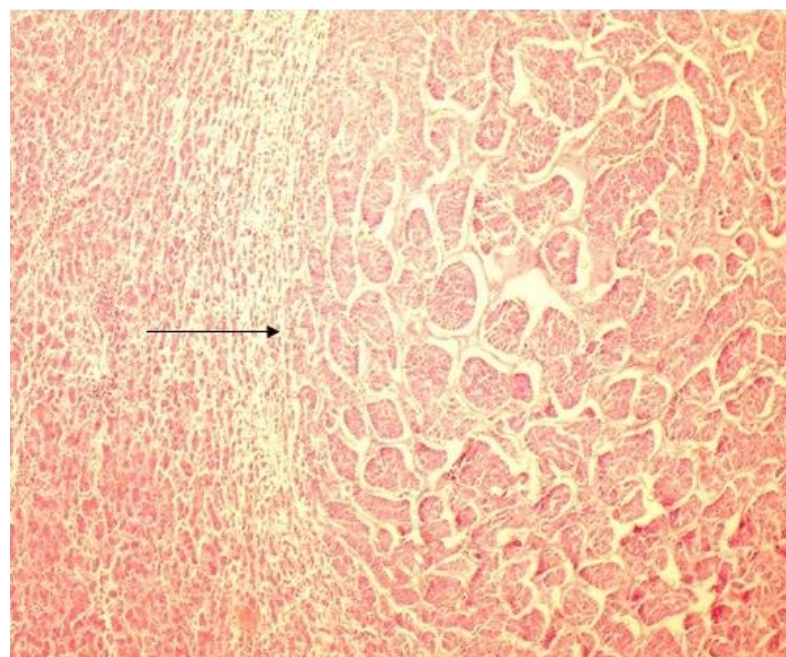

Figura 3. Fígado com sertolioma metastástico no parênquima (seta) (HE100x).

\section{DISCUSSÃO}

No presente caso, com base nos achados de necropsia e no exame histopatológico, concluiuse que a causa da morte do animal foi decorrente de hemorragia interna, em virtude da ruptura de vasos sanguíneos em um tumor de células de Sertoli no testículo direito. O sertolioma é uma neoplasia de crescimento lento e pouco invasivo, que geralmente apresenta comportamento benigno, porém, em alguns casos, pode ser maligno e ocasionar metástases em linfonodos inguinais, ilíacos e sublombares, além do pulmão, fígado, baço, rins e pâncreas (Santos e Angélico, 2004). No caso relatado, somente foram observados metástases no fígado.
Esses tumores frequentemente causam aumento de volume testicular e são descritos histologicamente como constituídos por células tumorais empaliçadas, longas e fusiformes, com prolongamentos citoplasmáticos finos e bordas celulares indistintas. Os núcleos são pequenos, hipocromáticos, alongados, redondos e ovais e são discretamente basofílicos. O citoplasma é vacuolizado e grânulos de pigmentos lipocrômicos nas células tumorais são frequentes. A superfície de corte é abaulada, e geralmente a sua coloração varia de cinzaesbranquiçada a amarela, bastante firme e até dura, similarmente ao encontrado no presente caso (Santos e Angélico, 2004). 
Os gansos sinaleiros (Anser cygnoides) pertencem à família Anseriforme, a qual apresenta menor frequência de neoplasias. Blackmore (1966) afirmou que casos de neoplasias são observados com maior frequência em Psittaciformes e Galliformes, porém raramente vistos em Columbiformes e Anseriformes, enquanto Reece (1992), em pesquisa realizada em laboratório de diagnóstico australiano, que incluía aves comerciais, de zoológico, de criadores, de vida livre e de companhia, encontrou $3,9 \%$ de incidência de tumores, sendo 58\% em Psittaciformes, $40 \%$ em periquito australiano (Melopsittacus undulatus), seguido de Passeriformes 14\%, Columbiformes $12 \%$ e Anseriformes $7 \%$.

Segundo Gorham e Ottinger (1986), em um estudo realizado em um lote de 33 codornas japonesas com mais de três anos de idade, $9,1 \%$ das aves tiveram um dos testículos neoplásicos. Estes testículos eram 2-5 vezes maiores que o tamanho normal, redondos e firmes, mostrando espaços císticos de tamanho variado. Beach (1962), em um estudo anterior, demonstrou que $58,5 \%$ (24) das neoplasias testiculares diagnosticadas (41) em periquitos e pássaros de gaiola eram de células tumorais de Sertoli. Desta forma, Gorham e Ottinger (1986) sugerem que os tumores de células de Sertoli possam ser uma neoplasia testicular aviária comum, embora afirmem que, em galinhas domésticas, a incidência de casos relatados de tumores testiculares é extremamente baixa, em virtude do pequeno percentual de machos que atingem a maturidade. Os autores também afirmam que a incidência de tumores testiculares em aves aumenta com a idade dos animais.

Em mamíferos, os tumores de células de Sertoli são associados, na maioria das vezes, com feminilização em virtude da produção de estrogênio. Características de feminilização em aves, tais como reversão de plumagem e mudança de comportamento sexual em periquitos e galináceos machos portadores de sertolioma, foram relatadas por vários autores (Beach, 1962; Reece, 1992). No caso da ave do presente trabalho, não é possível concluir se o tumor testicular teria produzido esse tipo de efeito, uma vez que, em gansos, o dimorfismo sexual não é evidente, a não ser em relação ao comportamento e à vocalização (Scott, 1997). Como o animal pertencia a um grupo criado em vida livre, essas características não puderam ser observadas.

A etiologia dos sertoliomas é desconhecida, mas a associação entre esse tipo de tumor e a infecção por poliomavírus em um diamante-de-Gould (Erythrura gouldiae) foi aventada por Rossi (2003), ao relatar o caso de ave do sexo masculino com três anos de idade que veio a óbito após apresentar letargia, emagrecimento, queda da plumagem e distensão abdominal. $\mathrm{O}$ tumor estava localizado no testículo esquerdo e, ao exame histopatológico, observou-se a presença de corpúsculos de inclusão intranucleares nas células neoplásicas. À microscopia eletrônica, tais corpúsculos correspondiam a agregados de partículas virais compatíveis com poliomavírus. No presente caso, não foram observados corpúsculos de inclusão nas células tumorais.

Distúrbios na coagulação sanguínea podem ocorrer como consequência de sertoliomas. Santos e Angélico (2004) observaram que cães acometidos desse tipo de neoplasia podem desenvolver depressão na medula óssea e hemorragias fatais. No presente trabalho, a morte da ave decorreu de profusa hemorragia a partir da neoplasia testicular.

$\mathrm{Na}$ literatura disponível não se encontrou relato da ocorrência de sertolioma em ganso sinaleiro, assim como não há menção à possibilidade de hemorragia interna grave em casos de sertolioma em aves. Dessa forma, relata-se pela primeira vez, ao que consta, a morte súbita de um ganso sinaleiro por hemorragia interna decorrente da ruptura de vasos sanguíneos em um sertolioma unilateral envolvendo o testículo direito e com presença de metástase no fígado.

\section{REFERÊNCIAS}

BEACH, J.E. Diseases of budgerigars and other cage birds. Vet. Record, v.74, p.63-68, 1962.

BLACKMORE, D.K. The clinical approach to tumors is cage birds. I. The pathology and incidence of neoplasia in cage birds. J. Small Anim. Pract., v.7, p.217-223, 1966.

GANORKAR, A.G.; KURKURE, N.V. Bilateral seminoma in a duck (Anas platyrhyunchos). Avian Pathol., v.27, p.644-645, 1998. 
GORHAM, S.L.; OTTINGER, M.A. Sertoli cell tumors in Japanese quail. Avian Dis., v.30, p.337-339, 1986.

LUNA, L.G. Manual of histologic staining methods of the Armed Forces Intitute of Pathology. New York: MCGRAW-HILL, 13.ed 1968. p. 258.

MUTINELLI, F.; VASCELLARI, M.; BOZZATO, E. Unilateral seminoma with multiple visceral metastases in a duck (Anas platyrhyunchos). Avian Pathol., v.35, p.327-329, 2006.

PETRAK, M.L.; GILMORE, C.E. Neoplasms. In: PETRAK, M.L. (Ed). Diseases of Cage and Aviary Bird. Philadelphia, PA: LEA \& FEBIGER.,1982. p.606-637.

REECE, R.L. Observations on naturally occurring neoplasms in birds in the state of Victoria, Australia. Avian Pathol., v.21, p.3-32, 1992.
ROSSI, G.; CECCHERELLI, R.; PIERSIGILLI, A.; TARANTINO, C. Sertoli cell tumor associated with polyomavirus infection in a gouldian finch (Erythrura gouldiae). Avian Dis., v.47, p.240-243, 2003.

SANTOS, P.C.G.; ANGÉLICO, G.T. Sertolioma - Revisão de Literatura. Rev. Cient. Elet. de Med. Vet., 2.ed. 2004. Disponível em: <http://www.revista.inf.br/veterinaria02/revisao/r evisao01.pdf>. Acessado em: 04 maio 2012.

SCOTT, T.A.; MERCER, I. Concise Encyclopedia of Biochemistry and Molecular Biology. New York: WALTER DE GRUYTER, 3.ed, 1997. $737 \mathrm{p}$.

SILLER, W.G. A Sertoli cell tumor causing feminization in a brown leghorn. J. Endocrinol., v.14, p.197-203, 1956. 